\title{
Development of Algorithms for Capacitance Imaging Techniques for Fluidized Bed Flow Fields
}

\section{1}

Annual Report

\section{Wilma Jean Loudin}

January 1992

Work Performed Under Contract No.: DE-FC21-87MC24207

For

U.S. Department of Energy

Office of Fossil Energy

Morgantown Energy Technology Center

Morgantown, West Virginia

By

West Virginia University Department of Mathematics Morgantown, West Virginia 


\section{DISCLAIMER}

This report was prepared as an account of work sponsored by an agency of the United States Government. Neither the United States Government nor any agency thereof, nor any of their employees makes any warranty, express or implied, or assumes any legal liability or responsibility for the accuracy, completeness or usefulness of any information, apparatus, product, or process disclosed, or represents that its use would not infringe privately owned rights. Reference herein to any specific commercial product, process, or service by trade name, trademark, manufacturer, or otherwise, does not necessarily constitute or imply its endorsement, recommendation, or favoring by the United States Government or any agency thereof. The views and opinions of authors expressed herein do not necessarily state or reflect those of the United States Government or any agency thereof.

This report has been reproduced directly from the best available copy.

Available to DOE and DOE contractors from the Office of Scientific and Technical Information, P.O. Box 62, Oak Ridge, TN 37831; prices available from (615)576-8401, FTS 626-8401.

Available to the public from the National Technical Information Service, U.S. Department of Commerce, 5285 Port Royal Rd., Springfield, VA 22161. 
Development of Algorithms for Capacitance Imaging Techniques for Fluidized Bed Flow Fields

1991

Annual Report

Wilma Jean Loudin

Work Performed Under Contract No.: DE-FC21-87MC24207

\author{
For \\ U.S. Department of Energy \\ Office of Fossil Energy \\ Morgantown Energy Technology Center \\ P.O. Box 880 \\ Morgantown, West Virginia 26507-0880 \\ By \\ West Virginia University \\ Department of Mathematics \\ Morgantown, West Virginia 26506
}

January 1992 


\section{Table of Contents}

Section No.

Page No.

1. Executive Summary $\ldots \ldots \ldots \ldots \ldots \ldots \ldots \ldots \ldots \ldots \ldots$

2. Introduction $\ldots \ldots \ldots \ldots \ldots \ldots \ldots \ldots \ldots \ldots \ldots \ldots \ldots$

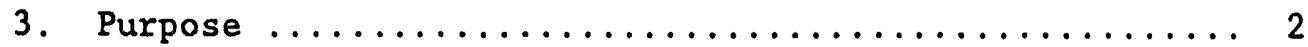

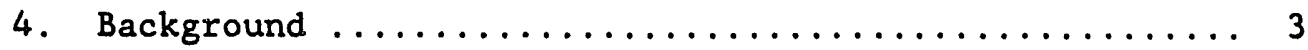

5. Methodology, including Quality Control .......... 4

6. Results and Discussion .................. 7

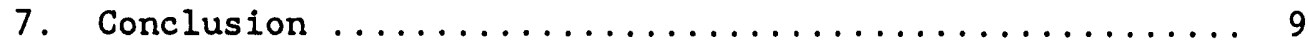

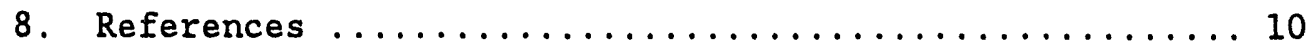

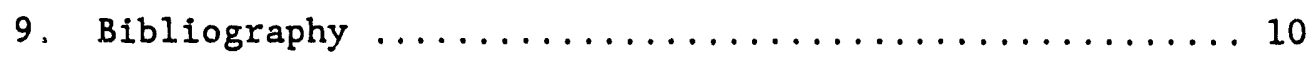


Table No.

Page No.

1 List of Mathematical Methods ............. 11

2 Comparison of Error Estimates for

Methods 1, 2, and $3 \ldots \ldots \ldots 12$

List of Figures

Figure No.

Page No.

$1 \quad$ Pixel Definitions $\ldots \ldots \ldots \ldots \ldots \ldots \ldots \ldots \ldots \ldots$

2 Method 1 - One Rod and Two Rod Calibrations ..... 14

3 Method 2 - One Rod and Two Rod Calibrations ..... 15

4 Method 3 - One Rod and Two Rod Calibrations ..... 16

5 Comparison of Methods for a One Rod Calibration .. 17

6 Comparison of Methods for a Two Rod Calibration .. 18

7 Comparison of Methods for Fluidization Data ..... 19

8 Comparison of Methods for Fluidization Data ..... 20 


\section{EXECUTIVE SUMMARY}

The objective of this research is to provide support for the instrumentation concept of a High Resolution Capacitance Imaging System (HRCIS). The work involves the development and evaluation of the matheratical theory and associated models and algorithms which reduce the electronic measurements to valid physical characterizations.

The research and development require the investigation of techniques to solve large systems of equations based on capacitance measurements for various electrode configurations in order to estimate densities of materials in a cross-section of a fluidized bed. Capacitance measurements are made for 400 connections of the 32-electrode system; 400 corresponding electric-field curves are constructed by solving a second order partial differential equation. These curves are used to partition the circular disk into 193 regions called pixels, and the density of material in each pixel is to be estimated.

The HRCIS work plan called for development of three mathematical models for estimating densities in a fluidized bed. These models are referred to as Methods 1, 2, and 3. Additional methods, designated Methods 4 through 9, were suggested during this reporting period. See Table 1 for a list of the methods included in the projzet, along with a brief description of each method.

1 - The square root of product method (Method 1) is a nonlinear method based on products of displacement currents for intersecting electric-field curves on a cross section. For each pixel one point of intersection is chosen, and the product of the capacitance measurements is found. Both the product and the square-root-of-product seem to yield good relative distribution of densities.

2 - The second mathematical model (Method 2) is based on a system of 400 linear equations in 193 variables where the variables represent densities in the 193 pixels. Several computer algorithms have been designed for establishing the coefficient matrix of the system and for solving the system. During this reporting period the programs were edited to scale the theoretical calibration densities to a maximum non-dimensional value of 1000 in place of the assumed value of 410 previously used. When the main program was restarted the sum of squares error in fitting calculated densities to assumed densities for known positions of nylon rods was large compared with values which had been attained.

3 - The third model (Method 3) is mathematically similar to the second model in that it consists of linear systems of equations. The principal difference is that the Method 2 systems are solved directly for densities while the Method 3 systems are solved for matrix coefficients; after the coefficients are found, the calculation of densities requires only a matrix multiplication. Method 3 yields very good least-squares fit to the calibration data. Because a single system to represent all 193 pixels would be very large using this method, the development has been done for one ring (or annulus) of 32 pixels at a time. The size of the system of equations for a ring depends on the number of sets of calibration data used: for four 
calibration sets the system is $129 \times 128$, and for eight calibration sets it is $257 \times 256$. The center pixel is treated separately with a $5 \times 5$ system using four calibration sets.

\section{INTRODUCTION}

For the High Resolution Capacitance Imaging project the first mathematical problem was to estimate the components of electric-field vectors where the field results from excitation of electrodes surrounding a fluidized bed. Thirty two electrodes are symnetrically placed at the outside diameter of a cross-section of the cylindrical bed; one set of data is made up of displacement currents measured between 400 pairs of electrodes (Fasching, G.E. and N.S. Smith, 1990). Boundary-value problems including the Laplace partial differential equation have been used in the modeling: solutions yield equipotential curves from which twenty-five basic electric-field curves are constructed. Rotation of the basic curves is used to determine the 400 curves corresponding to the designated electrode connections.

The circular cross-section of the bed is partitioned into 193 subregions called pixels or cells as in Figure 1 . Numbers 1 to 32 around the circumference of the circle indicate the positions of the electrodes. The letters $A, B, C, D, E, F$, and $G$ label the rings of pixels. The notation "D8" corresponds to the pixel in the $D$ ring on a radius joining electrode number 8 to the center of the circle. Pixel D8 is also denoted by pixel number 73 . The A "ring" consists of only pixel number 1 .

\section{PURPOSE}

The basic question in the research is, "How can the density of material at each pixel location along the path of an electric-field curve be calculated?" The answer is being sought by several methods which have been tested on various data sets derived from the capacitance imaging system.

Several methods have been developed for estimating the density of material at each pixel; three of the methods are included in this report. The simplest method uses square roots of products of displacement currents to estimate relative densities over the cross-section. In the other two methods linear systems of equations are established and solved; HRCIS data sets provide the constant vectors in the Method 2 system of equations and the coefficient matrix in the Method 3 system.

The objective in using the linear systems of equations is to find sets of coefficients which may be applied repeatedly to produce density distribution vectors corresponding to HRCIS current displacement vectors. The product method is designed to provide intermediate (though probably less accurate) estimates of pixel densities while the coefficient sets are being optimized. 


\section{BACKGROUND}

The central problem in constructing the mathematical model for Method 2 is to reproduce within a computer program a chart representing the theoretical distribution of capacitance on a circular cross-section of a fluidized-bed. The chart is used to define 400 equations based on a 32-electrode configuration, where each equation represents a connection between two electrodes. For example, the first column of the chart connects the first and fourth electrodes and yields a linear equation of the form

$$
\sum_{j=1}^{193} \quad L_{i j} s_{j}=d_{1}
$$

For a given set of coefficients $L_{i j}$, $i$ from 1 to $400, j$ from 1 to 193 , and a given set of $d_{i}$, the 400 equations are determined. The number of unique coefficients $L_{i j}$ has been varied from 47 in initial models to 626 in the current model. Each $L_{i j}$ may be used several times; for example, $L_{26,192}=$ $\mathrm{L}_{26,163}=\mathrm{L}_{1,165}=\mathrm{L}_{1,162}$. There are 25 normalizing constraints which require that the sum of the coefficients appearing in any column of the chart be equal to one; if a coefficient appears more than once, it is counted the number of times it occurs.

In the system As = d of 400 equations, the 193 components of vector $s$ represent the density distribution of material in a cross-section of the bed. The circular disk has been partitioned into 193 subregions or pixels as shown in Figure 1. Density in the innermost circular region is also designated by $A$, i.e., $s_{1}$ - A. Density in the circular ring or annulus surrounding $A$ is also designated by $B, i . e,, s_{2}=B_{1}, s_{3}=B_{2}, \ldots, s_{33}=B_{32}$. The $C, D, E, F$, and $G$ regions are similarly defined with $s_{130}=F_{1}, s_{131}=F_{2}, \ldots, s_{161}=$ $F_{32}$, and $s_{162}=G_{1}, s_{163}=G_{2}, \ldots, s_{193}=G_{32}$.

The 400 components of vector d represent displacement currents which are measured experimentally. In each set of experiments there are tests called calibrations which are designed for determining the coefficients. A one-void calibration is a set of HRCIS measurements taken with an object such as an plastic bottle filled with motor oil or a solid nylon rod placed upright in a certain position within the cylinder so that a circular cross-section of the cylinder will contain a circular cross-section of the bottle or rod. A two-void calibration is done with two solid nylon rods in the vessel. Rod sizes and positions are varied to provide different sets of calibration data. Currently, twelve sets of calibration data are being used to establish and test the mathematical models.

The computer program which sets up the matrix of coefficients $L_{i j}$ is called MAT400; all of the computer programs discussed in this report are written in Fortran for use on the VAX 8650 computer and the FPS array processor. In a typical case with 626 unique coefficients $L_{i j}$, the number of non-zero entries in matrix $A$ is 19,833 .

The mathematical model for Method 3 is set up in a similar way: for each ring, B to G, a system of 129 linear equations in 128 unknowns is established 
using four sets of calibration data. In Method 3, the HRCIS measurements go into the coefficient matrix, whereas in Method 2, the measurements are the right-hand-side constants in the system of equations.

Generally, systems which have more equations than unknowns are inconsistent, and that may be true here; if so, solutions can be estimated by using a least-squares procedure to minimize the length of the residual vector $r=d$ - As. A more limiting problem occurs when the system does not contain as many independent equations as the number of unknowns, perhaps due to the symmetries in the physical system (HRIIS). Changes in the positions of the nylon rods during calibration have been used to reduce this dependence.

The computer program to solve the system of equations is called SLE (for System of Linear Equations). SLE reads matrix A and vector d; then SLE calls a NAG (Numerical Algorithms Group) Fortran Library routine which carries out the minimization of the length of $r$. The NAG routine returns vector $s$ and an error measurement given by

$$
\sigma=\sqrt{\frac{r^{T} r}{m-k}} \text { where } r^{T} r \text { is the residual sum of squares, } m \text { is }
$$

the number of equations, and $k$ is the rank of $A$. (Lawson, C.L. and R.J. Hanson, 1974)

\section{METHODOLOGY, INCLUDING QUALITY CONTROL}

The High Resolution Capacitance Imaging System (HRCIS) is a 32-electrode system which measures displacement currents between pairs of electrodes at the rate of 25,000 measurements per second. The HRCIS charts list 400 pairs of electrode connections to establish a system of 400 linear algebraic equations for a particular time frame so there are about 60 frames of data for each second. Data collections are referred to as standardization, calibration, and fluidization. Calibration data is collected when one or more objects of known size and shape are placed in the six-inch diameter fluidization vessel. Currently, one or two cylindrical nylon rods are used: a typical one-rod or one-void calibration is done with a three-inch diameter rod centered at pixel 56 (See Figure 1); a two-rod or two-void calibration might be done with the three-inch rod placed as before and a one-and-one-half inch diameter rod centered at pixel 102.

Both the product method and the linear transformation methods for determining density distributions use a partitioning of a circular crosssection of the fluidization vessel into subregions called pixels. Figure 1 shows the current partitioning of the 6-inch diameter cross-section into 193 pixels. Numbers 1 to 32 around the circumference of the circle indicate the positions of the electrodes. The notation "D8" corresponds to the pixel with radial measurement between 1.5 and 2.0 inches and angular measurement between $\pi / 2$ and $9 \pi / 16$ radians. Pixel $D 8$ is also denoted by pixel number 73 . 
Application of the product method (Method 1) required:

(1) the generation of 25 basic electric-field curves used to represent the 400 connections of electrodes

(2) a search for the points of intersection of the 400 curves (more than 20,000 points were found)

(3) sorting of points of intersection according to pixel location and choosing those points which would yield the best representation of data

(4) calculation of the square root of the product of two displacement current measurements.

The square-root-of-product method is used in the real-time display of HRCIS data on a black and white monitor which shows density variation by shading of pixel areas using white for lowest density and black for highest density; the system also uses a color monitor.

The second mathematical model (Method 2) applied to the HRCIS data consists of a system of linear equations to be established and then to be solved. Currently, the model has 400 equations with the 193 pixel densities as variables. Charts which show the construction of the system have been provided and have been used to set up the equations. The most significant problem associated with this method is that of finding the coefficients which make up the matrix $A$ in the system of equations denoted by $A x=b$ or $A s=d$ where $x$ or $s$ is the column vector of 193 unknown densities, and $b$ or $d$ is the column vector of displacement current measurements. Computer programs have been written to set up the system $A x=b$ according to the charts and to solve the system of equations.

The following procedures have been used to optimize the coefficients which go into matrix A:

(1) The system $A x=b$ was converted to a similar system labeled by $D L=b$. The size of this system is 425 by 349 , that is, it consists of 425 equations in 349 variables. The first 400 equations were the same as in $A x=b$, with the roles of coefficients and variables interchanged, and the additional 25 equations imposed so-called normalizing constraints on the coefficients: the sum of the coefficients in any column of the charts must be one unit. The matrix $D$ is an array of theoretical density values based on cross-sections of one or two nylon rods being superimposed on the circular cross-section of the fluidization vessel. Vector $I$ represents the 349 variable coefficients. In both systems the vector $b$ contains the 400 displacement current measurements from the HRCIS; in the second system these 400 measurements were supplemented by appending the 25 ones required for normalization. For the $D L=b$ system, vector $b$ is given by calibration data. $D L=b$ is solved by the same least-squares procedure that is used to solve $A x=b$. 
(2) A column by column search of the HRCIS electrode connection charts showed that in a few columns the number of variable coefficients exceeded the number of constraints on those coefficients; therefore, coefficients which were judged least significant were deleted. The density maps produced after this change showed definite improvement over maps produced earlier. Therefore, the process of deleting coefficients was continued in an effort to further improve the maps. A computer program which eliminated coefficients, one or two at a time, was constructed. The objective was to choose from a basic set of 349 coefficients the subset which would produce the best least-squares fits to two sets of calibration data. Initially, 59 coefficients were dropped because their estimated values had been smallest; then 39 of those coefficients were restored due to indications that some of them were more important than their relative values reflected; finally, contributions of the remaining 25 coefficients were reconsidered.

(3) The computer program which eliminated coefficients was modified to adjust coefficients instead of dropping them. One coefficient at a time was incremented six times ( 3 increases, 3 decreases), the two-rod sum of squares was calculated for each increment, and a parabola was fitted to the data (coefficient value vs sum of squares) for the prediction of a new low point. For this coefficient, the resulting eight points were compared, the one with the least sum was kept, and the program moved to the next coefficient. After several program runs were made, the number of increments was cut from six to two in order to save computer time; the use of the parabola proved to be very effective, and only the starting point and two new points were required for its determination. Program output includes sum of squares for each set of calibration data, the sum of the absolute values of all coefficients, the sum of the coefficients in each column of the charts, the average change in density over 193 pixels, and the ratio of the two-rod sum of squares to the average change in density.

The third HRCIS mathematical model (Method 3) for determining pixel densities is similar to Method 2, but it is a more extensive system. Each of the six rings and the one center pixel are treated independently: for each ring of pixels a system of 257 equations in 256 variable coefficients is established and solved, and for the center pixel a system of 9 equations in 8 variable coefficients is used, for a total of 1551 equations in 1544 variables. These equations are based on eight sets of calibration data although initially only two and then four calibrations were used.

For Method 3 the matrix equation for a ring of pixels is constructed in the form $I k=d$, where $I$ is a 257 by 256 matrix of calibration measurements, $k$ is a 256 by 1 column of variable coefficients, and $d$ is a 257 by 1 column of theoretical densities based on the calibration configuration. After the coefficients have been calculated using this system, the system is used again for data other than calibration data. For fluidization data, for example, the matrix I will be made up of fluidization measurements, and corresponding 
densities will be given by the matrix multiplication $d=$ Ik.

The following procedures have been used for each ring (Method 3):

(1) Choose 16 of 25 columns established by the HRCIS charts (Choice of columns determines which HRCIS measurements will appear in linear system of equations, 16 measurements per column).

(2) Set up and solve system of linear equations: 257 equations in 256 unknown coefficients.

(3) Calculate densities for the eight input calibration configurations (training data) to check accuracy.

(4) Calculate densities for four additional sets of HRCIS calibration measurements (test data).

Repeat steps (1) to (4) for many combinations of 25 columns taken 16 at a time. Program output for each trial includes a list of the 256 calculated coefficients, the sum of the absolute values of the coefficients, the sum of the squares of the coefficients, and the sum of the squares of the deviations from known densities for the calibrations in steps 3 and 4.

Based on minimizing the sum of squares of deviations for the training data, the best results were averaged to produce still better estimates of the calibration densities. The number of cases averaged was varied from 2 to 40; the lowest error has generally been obtained when 5 to 12 cases were averaged.

A computer program has been developed to provide an optional angular digital filter to reduce the effect of measurement-system noise. The filter can be applied to the input data and/or to the output data for each of the methods discussed above.

A strong effort has been made to control and assure the quality of work on this project. Post-run analyses are compared with real-time displays to provide a check on all the routines. Results of the various methods are compared in order to assess the strengths and weaknesses of each method. To test the computer programs for solving systems of equations, the programs are applied to systems with known solutions, and the results are verified. Weekly meetings are held with METC personnel working on the project to discuss the validity of numerical results.

\section{RESULTS AND DISCUSSION}

During this reporting period, the principal objectives in the numerical analysis for the HRCIS project have been (1) to improve Method 2 and (2) to introduce an additional linear transformation method, Method 3, for estimating densities of materials in a fluidized bed. Calibration measurements are frequently taken to provide bases for the calculations. Initially, calibration was done with one upright cylindrical rod placed in the 
fluidization vessel, and later two rods were used. Currently, both types of calibrations are being used to develop the transformation models. Improvement in the models is dependent on the reduction of the sum of squares errors in matching the assumed calibration positions to the calculated density distributions for calibrations.

The computer algorithms for Method 2 have been designed as a two-siep process to produce a reduction in the total sum of squares (one-rod plus two-rod): the first is to change the calculated densities by incrementing coefficients in the matrix $A$ for the 400 by 193 system $A x-b$; the second is to alter the assumed calibration positions. The number of unique coefficients in matrix $A$ has recently been increased from 349 to 626 through adjustments in the HRCIS charts. The original approach was to solve the system DL = b (See Item 5, pages 5 and 6 ) for 349 variable coefficients, and then to increment them one at a time. As the 277 new coefficients were added to the system they were set at zero, and then incremented and tested along with the original ones.

The change in assumed calibration positions is made in a computer program called CALROD which has been updated from a 97-pixel application to 193-pixel application. This program provides theoretical density distribution for a given location of a rod used for calibration.

A significant change has recently been made in the application of Method 2: the assumed maximum for calibration density was increased from 410 to 1000 (dimensionless units); the 410 standard was based on Method 1 results whereas the 1000 standard is based on the method of reading and scaling input HRCIS measurements; the new standard appears to be a more realistic one.

A Gaussian digital filter has been applied to the theoretical one-rod and two-rod density and to the calculated density distributions to smooth the data. Using the standard maximum density of 410, the filter constant was increased from 0.7 to 1.5 in increments of 0.2 . After each increase the calculated calibration densities were plotted to determine whether or not the change resulted in a significant loss of resolution. Through repeated applications of the programs the root-mean-square errors were reduced by the following amounts:

$$
\begin{array}{rrr}
\text { One-rod calibration from } & 4.18 & \text { with filter constant } 0.7 \\
\text { to } & 1.48 & \text { with filter constant } 1.5 ; \\
& & \\
\text { Two-rod calibration from } & 4.78 \text { with filter constant } 0.7 \\
\text { to } & 1.98 \text { with filter constant } 1.5 .
\end{array}
$$

When the program was restarted with the standard maximum increased to 1000 , and for a 0.7 filter constant, the errors jumped to 7.78 for the one-void calibration and to 12.28 for the two-void calibration; over five months those errors have dropped to 4.38 and $5.0 \%$, respectively.

Development of Method 3 has produced very good results in terms of sum-of-squares errors in matching calibration data. The method was first set 
up for the same two calibrations as used in Method 2, but was expanded to include six additional calibrations. One advantage of Method 3 over Method 2 is the easy inclusion of additional calibrations.

Figures 2 to 4 show comparisons of the theoretical density distributions with results from each of the Methods 1, 2, and 3 for the same sets of one-rod and two-rod input calibration data.

Figures 5 and 6 show the applications of the three methods to a common set of two-rod calibration data used for checking the methods.

Table 2 provides a comparison of error estimates for Methods 1, 2, and 3, applied to common calibration data (four sets).

Figures 7 and 8 show the applications of the four methods to a common set of fluidization data where there is no theoretical distribution available.

The goals of (1) improving the resolution in Method 2 (numerically, this means reducing the sum of squares errors), and (2) developing Method 3 to optimize the choices of HRCIS columns and calibrations have been met.

Development of Methods 1, 2, and 3 will now be terminated, or at least suspended, in favor of one or more of the additional methods listed in Table 1 ; Methods 4 to 9 have been studied by this investigator and by other participants on the HRCIS project. Method 7 seems especially promising.

The HRCIS data used in this project was taken from a fluid bed system with a six inch circular cross-section. METC now has a twelve inch model. Initial data collection has been performed to check operation of the excitation and sense switch circuits in the system. Some of this data has been normalized, plotted, and compared with corresponding data from the six inch system.

\section{CONCLUSION}

As the METC HRCIS has been expanded from a 16-electrode system to a

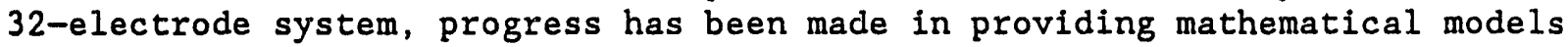
to complement the System, with revision and enlargment of some of the previously used computer software while new programs were developed as they were needed.

Based on a list - $f$ electrode-to-electrode measurements, corresponding electric-field curves have been constructed, and their points of intersection have been located. This process led to implementation of the square-root-ofproduct method for the HRCIS real-time display monitor and the linear transformation method for post-run analyses. Refinement of mathematical models has been achieved through least-squares processes applied to ( 1 ) choice of points of intersection for the product method, and (2) optimization of the coefficient matrix to set up the system of linear equations in the form $A x=b$. Improvements in the displays of density distributions for both methods have been made made through the application of digital filtering. It 
is expected that the linear transformation methods provide a more accurate model for the physical system than the product method yields.

During this reporting period emphasis has been placed on improvement of the linear transformation methods. For Method 2 a two-step process of (1) changing entries in the coefficient matrix, and (2) increasing the filter constant to reduce the effects of HRCIS noise has proved effective in reducing the least-squares error in obtaining matches to calibration data. Method 3 is a variation of the linear transformation method; this newly developed method allows for simultaneous use of up to eight sets of calibration data.

\section{REFERENCES}

Fasching, G.E., and N.S. Smith, "High Resolution Capacitance Imaging System," Technical Report DOEMETC8840083, September, 1988

Fasching, G.E., and N.S. Smith, "Three-Dimensional Capacitance Imaging System," Technical Note DOE/METC-90/4097 (DE90000470), April, 1990

Lawson, C.L., and R.J. Hanson, Solving Least Squares Problems, Prentice-Hall, New Jersey, 1974

\section{BIBLIOGRAPHY}

Burden, R.L., and J.D. Faires, Numerical Analysis, Third Edition, Prindle, Weber, and Schmidt, Boston, 1985

Fasching, G.E., D.R. Goff, and D.A. Maxfield, "Design and Performance of a Capacitance Probe for Monitoring Averaged Parameters and Individual Events in a High-Temperature, Fluidized-Bed Reactor," Technical Report DE82020148, Morgantown Energy Technology Center, Morgantown, WV, July, 1982

Fox, L., An Introduction to Numerical Linear Algebra, Oxford University Press, New York, 1965

Gelenbe, Erol, and Andreas Stafylopatis, "Global Behavior of Homogeneous Random Neural Systems," Applied Mathematical Modeling, Volume 15, No. 10, pp. 534-541, October, 1991

Leon, S.J., Linear Algebra with Applications, Third Edition, Macmillan, New York, 1990 
TABLE 1. LIST OF MATHEMATICAL METHODS

CAPACITANCE IMAGING SYSTEM

\begin{tabular}{|c|c|c|}
\hline METHOD & LINEAR/NONLINEAR & CALIBRATIONS (INPUT) \\
\hline 1 & $\begin{array}{l}\text { nonlinear, square } \\
\text { root of product }\end{array}$ & S38 (1) \\
\hline 2 & $\begin{array}{l}\text { linear }(400 \times 193) \\
I d=i\end{array}$ & $549(1,2)$ \\
\hline 3 & $\begin{array}{l}\text { linear (257x256, per ring) } \\
\text { I } k=d\end{array}$ & $\begin{array}{l}S 49(1,2) \\
\operatorname{S5} 5(5,6,7,8,9,10)\end{array}$ \\
\hline 4 & nonlinear network & \\
\hline 5 & $\begin{array}{l}\text { nonlinear network } \\
\text { flux tube densities from } \\
\text { Method } 1\end{array}$ & \\
\hline 6 & $\begin{array}{l}\text { linear (258x68, or smaller) } \\
\text { flux tube densities from } \\
\text { Method } 1 \\
\quad D \mathrm{~m}=\mathrm{d}\end{array}$ & $\begin{array}{l}S 49(1,2) \\
\operatorname{S55}(5,6,7,8,9,10)\end{array}$ \\
\hline 7 & $\begin{array}{l}\text { nonlinear network } \\
\text { all densities }\end{array}$ & $\operatorname{S55}(3,4,5,6,7,8,9,10)$ \\
\hline 8 & $\begin{array}{l}\text { linear (257x103, each ring) } \\
\text { all densities } \\
\qquad \mathrm{Dm}=\mathrm{d}\end{array}$ & $\begin{array}{l}\operatorname{S} 49(1,2) \\
\operatorname{S5} 5(5,6,7,8,9,10)\end{array}$ \\
\hline 9 & $\begin{array}{l}\text { nonlinear network } \\
\text { similar to Method } 3\end{array}$ & $\operatorname{S55}(3,4,5,6,7,8,9,10)$ \\
\hline
\end{tabular}

COMMON DATA SETS FOR CHECKING:

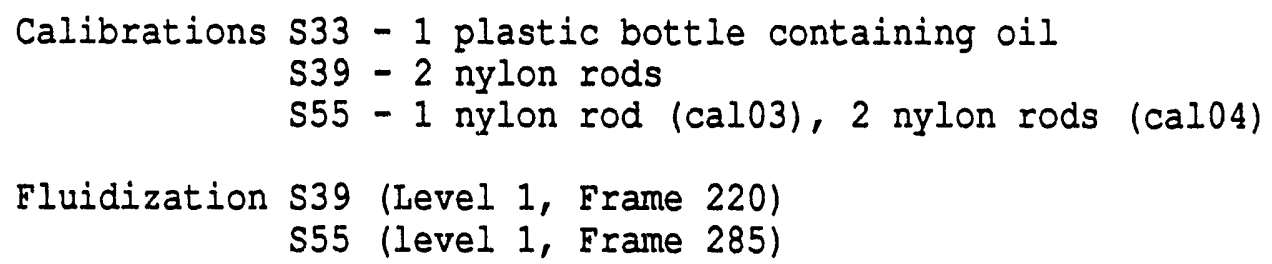


TABLE 2. COMPARISON OF ERROR ESTIMATES FOR METHODS 1, 2, AND 3

$\begin{array}{ccc}\text { METHOD } 1 & \text { METHOD 2 } & \text { METHOD } 3 \\ \text { PERCENT } & \text { PERCENT } & \text { PERCEN } \\ \text { ERROR } & \text { ERROR } & \text { ERROR }\end{array}$

DATA SET

1 ROD - S33 $\quad 40.2$

$23.7 \quad 21.8$

2 RODS - S39 $\quad 37.5$

$13.0 \quad 13.9$

1 ROD - S55 35.2

$18.3 \quad 15.6$

2 RODS - S55 37.8

14.9

13.6

FILTER CONSTANT: $\quad 0.70$

$\begin{array}{ccc}\text { METHOD } 1 & \text { METHOD 2 } & \text { METHOD } 3 \\ \text { PERCENT } & \text { PERCENT } & \text { PERCENT } \\ \text { ERROR } & \text { ERROR } & \text { ERROR }\end{array}$

DATA SET

$\begin{array}{llll}1 \text { ROD - S33 } & 38.4 & 22.2 & 19.7 \\ 2 \text { RODS - S39 } & 34.4 & 10.3 & 10.9 \\ 1 \text { ROD - S55 } & 33.4 & 15.6 & 11.6 \\ 2 \text { RODS - S55 } & 34.5 & 11.4 & 9.2\end{array}$

FILTER CONSTANT: 1.50 


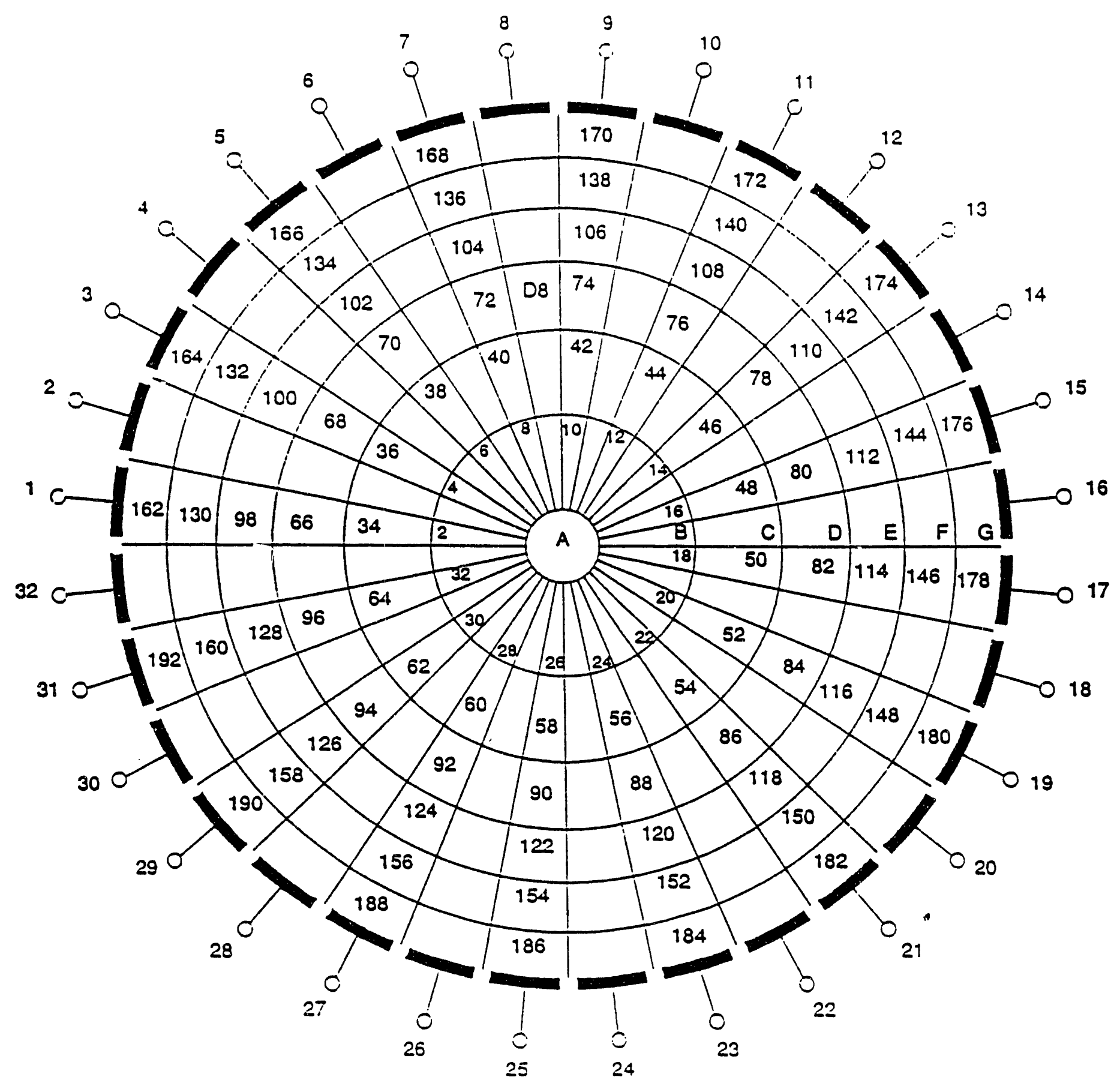

FIGURE 1. DIXEI DEIINITIONS 
ONE-ROD CALIBRATION DATA (S49)

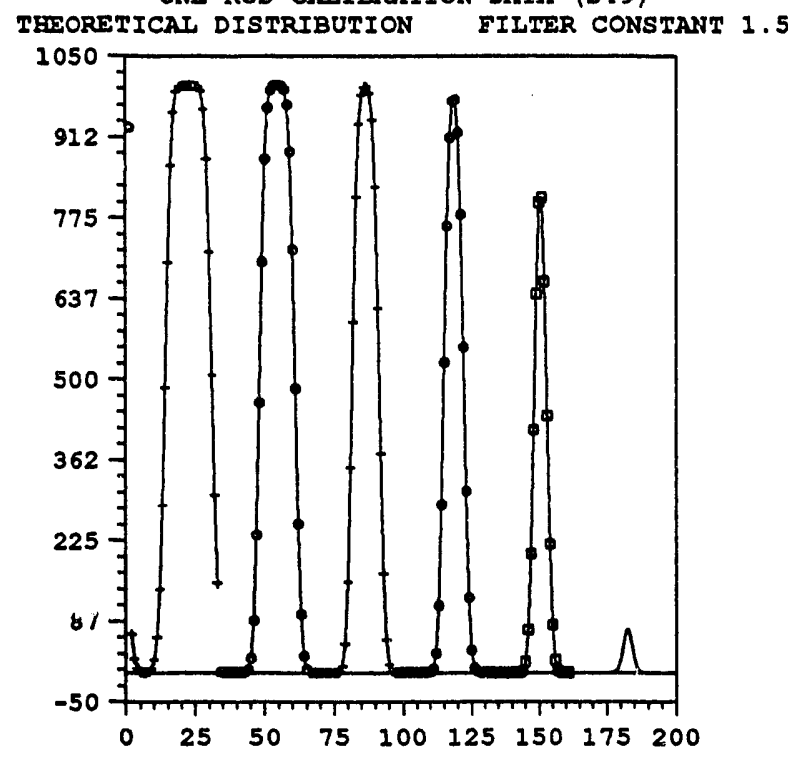

Pixel Number

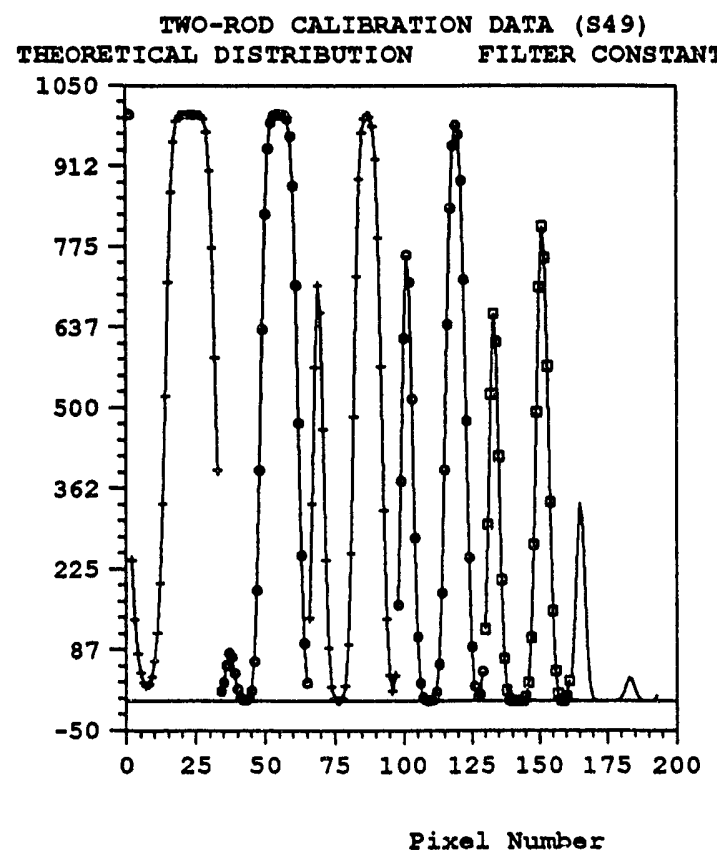

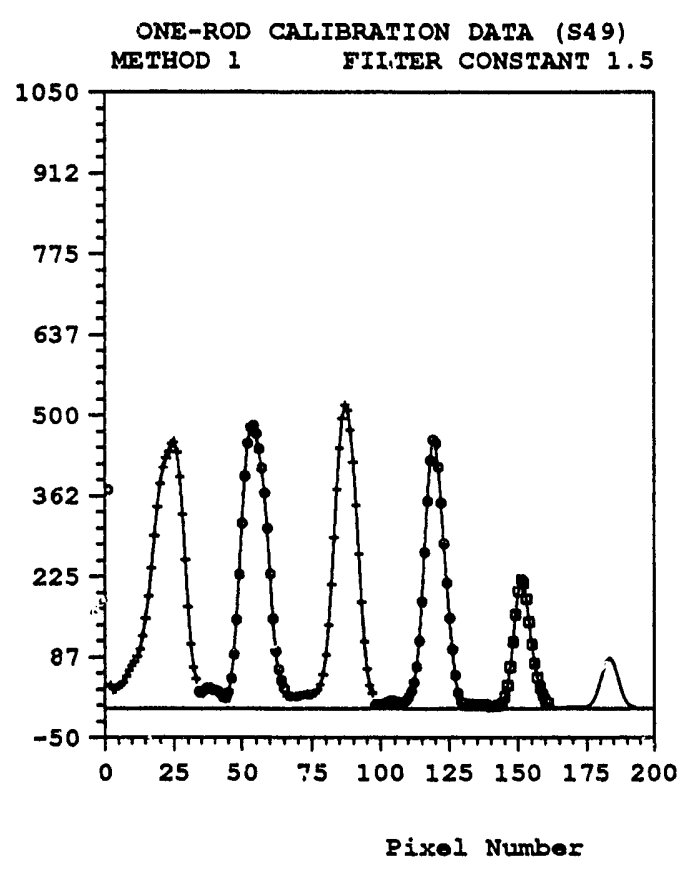

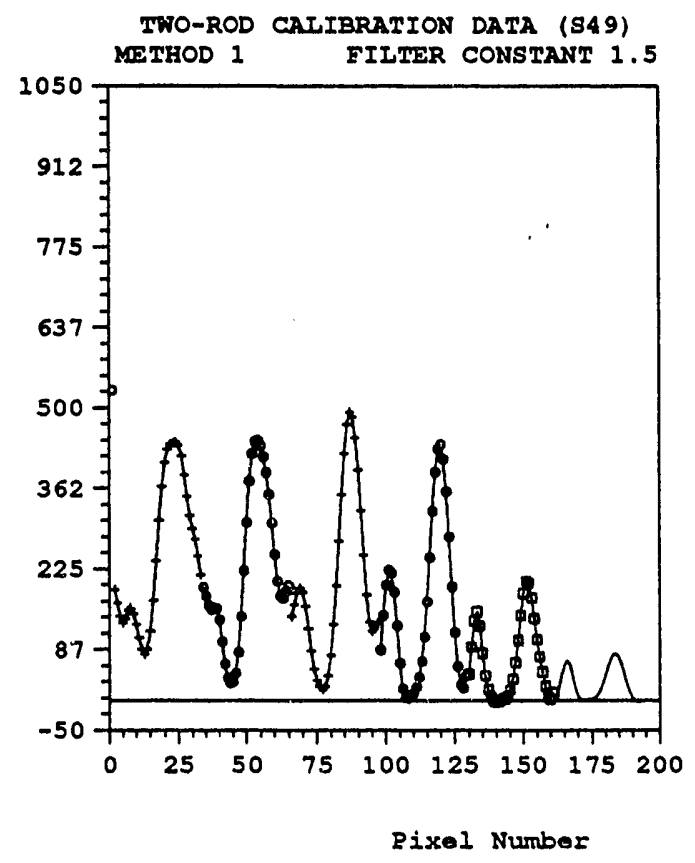

\section{FIGURE 2. METHOD 1}



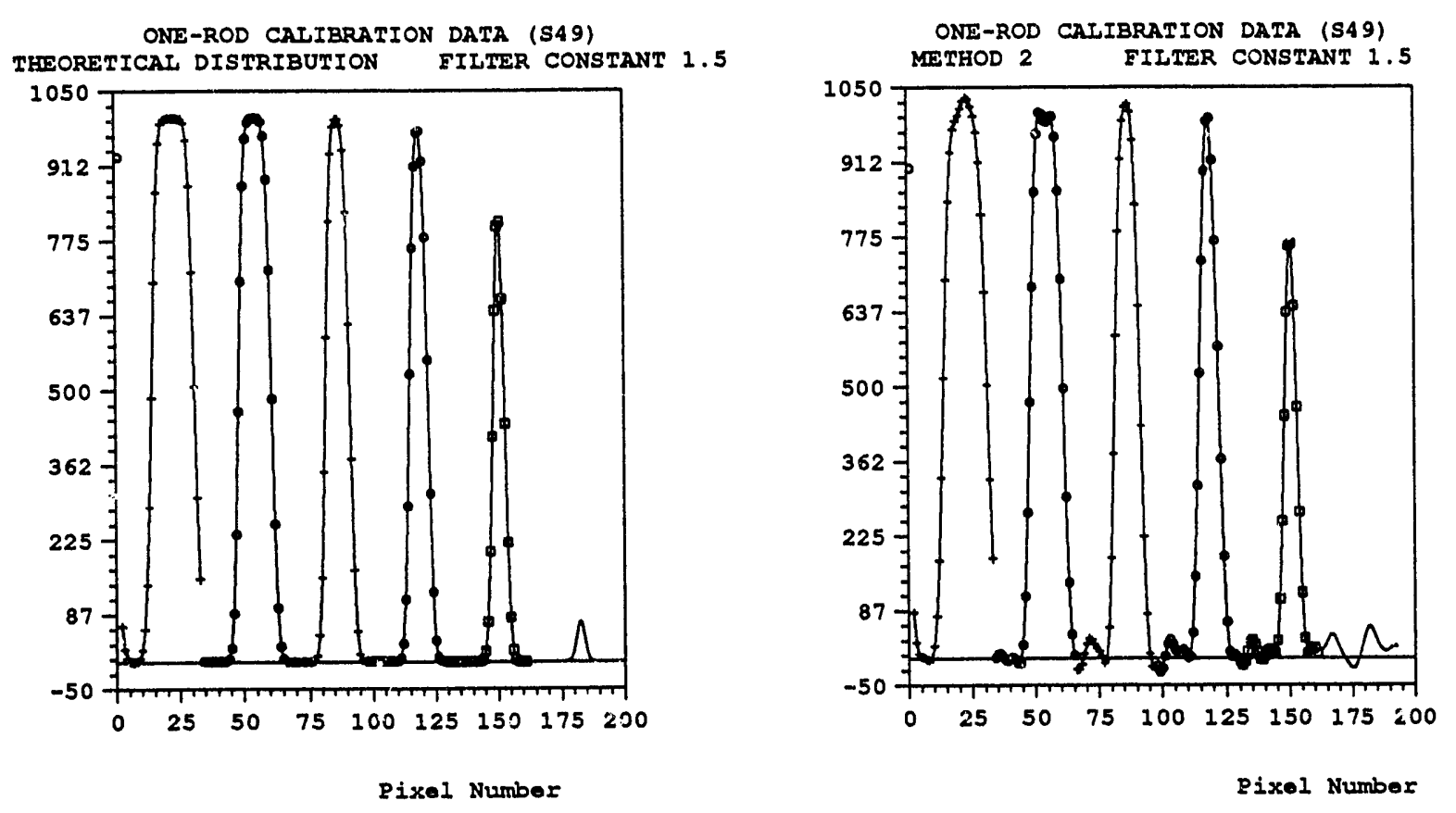

TWO-ROD CALIBRATIOU DATA (\$49)

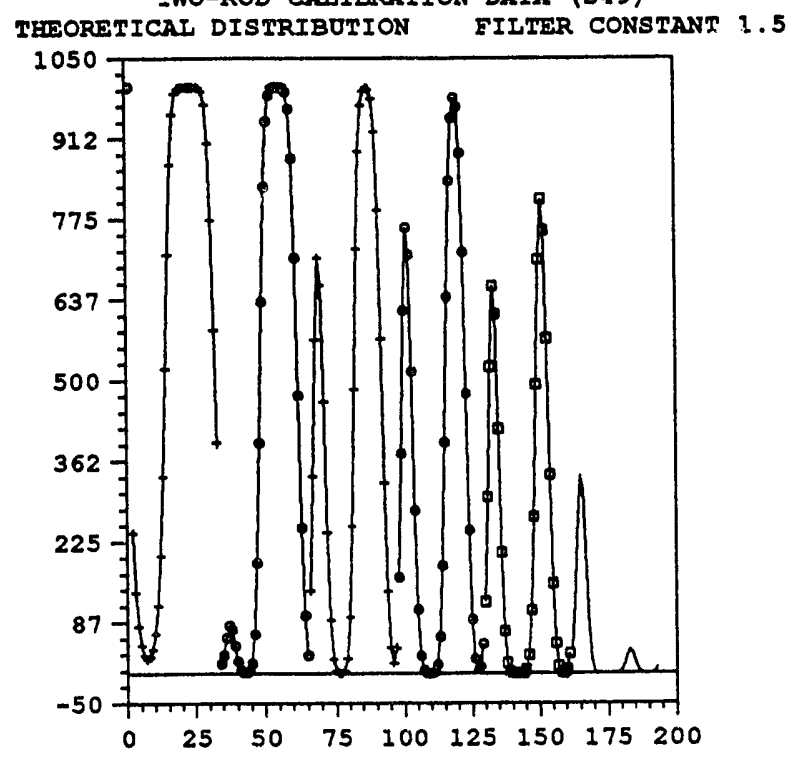

Pixel Number

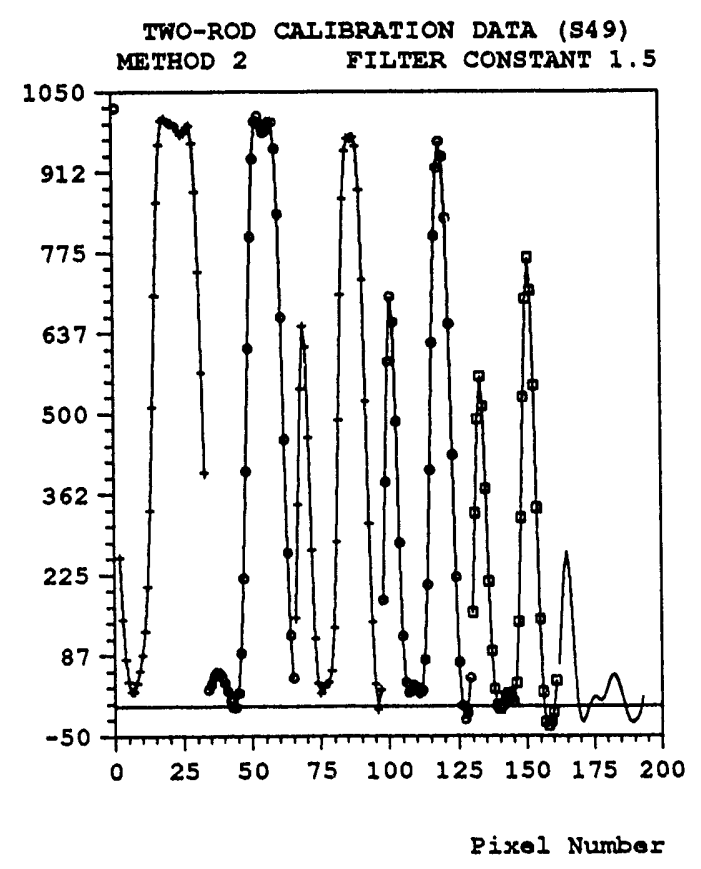

FIGURE 3. METHOD 2 

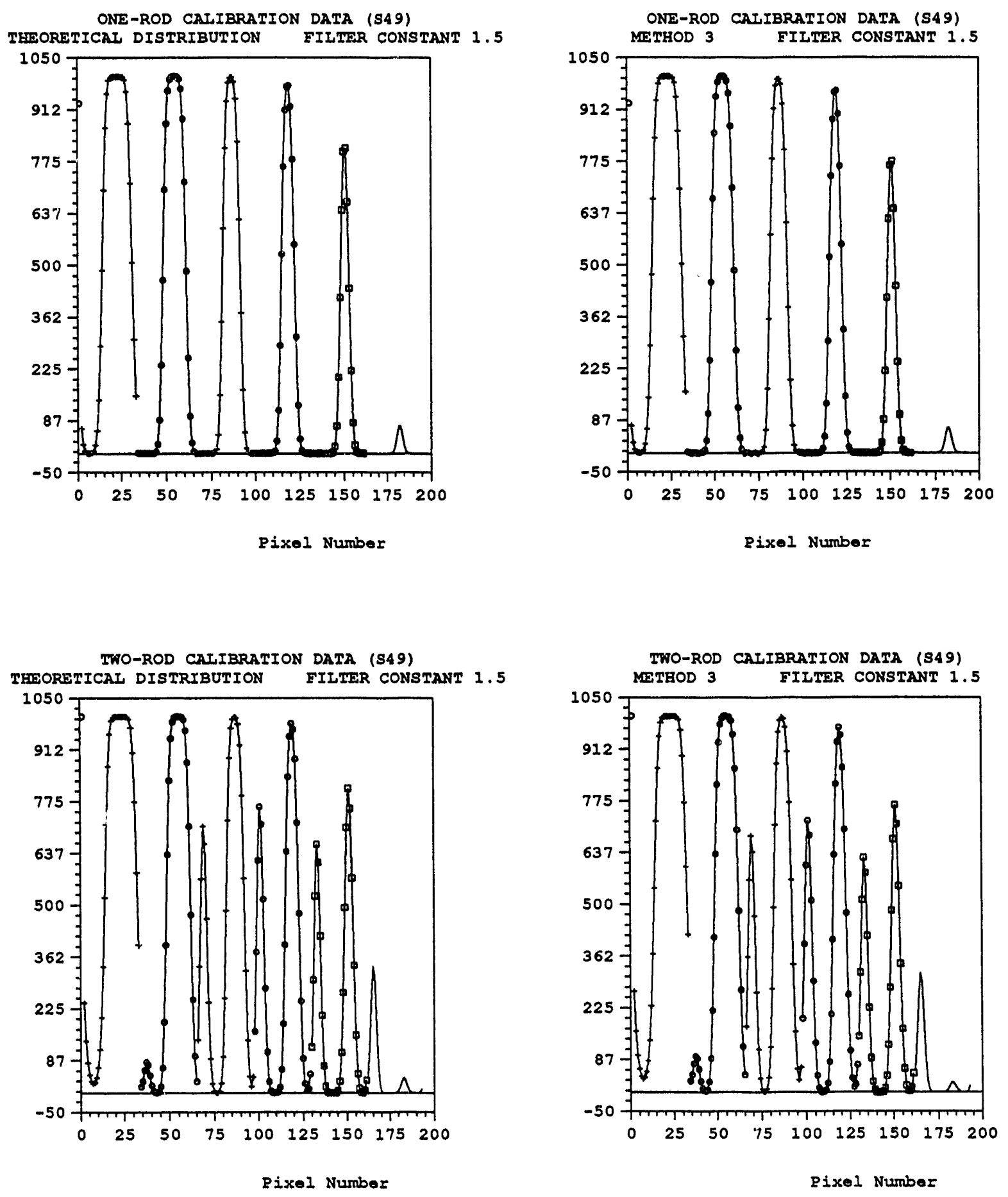

\section{FIGURE 4. METHOD 3}



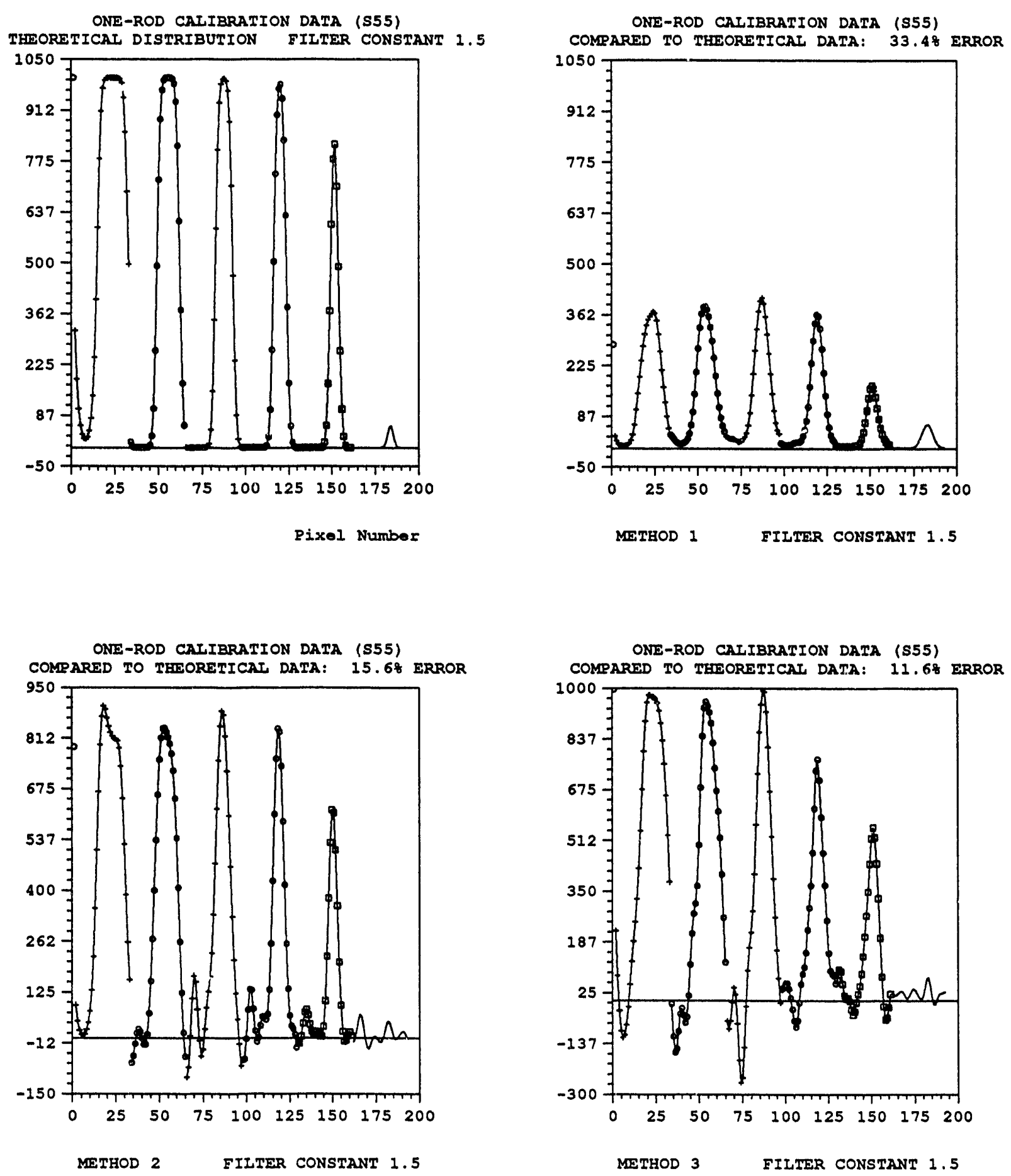

\section{FIGURE 5. COMPARISON OF METHODS FOR A ONE ROD CALIBRATION}



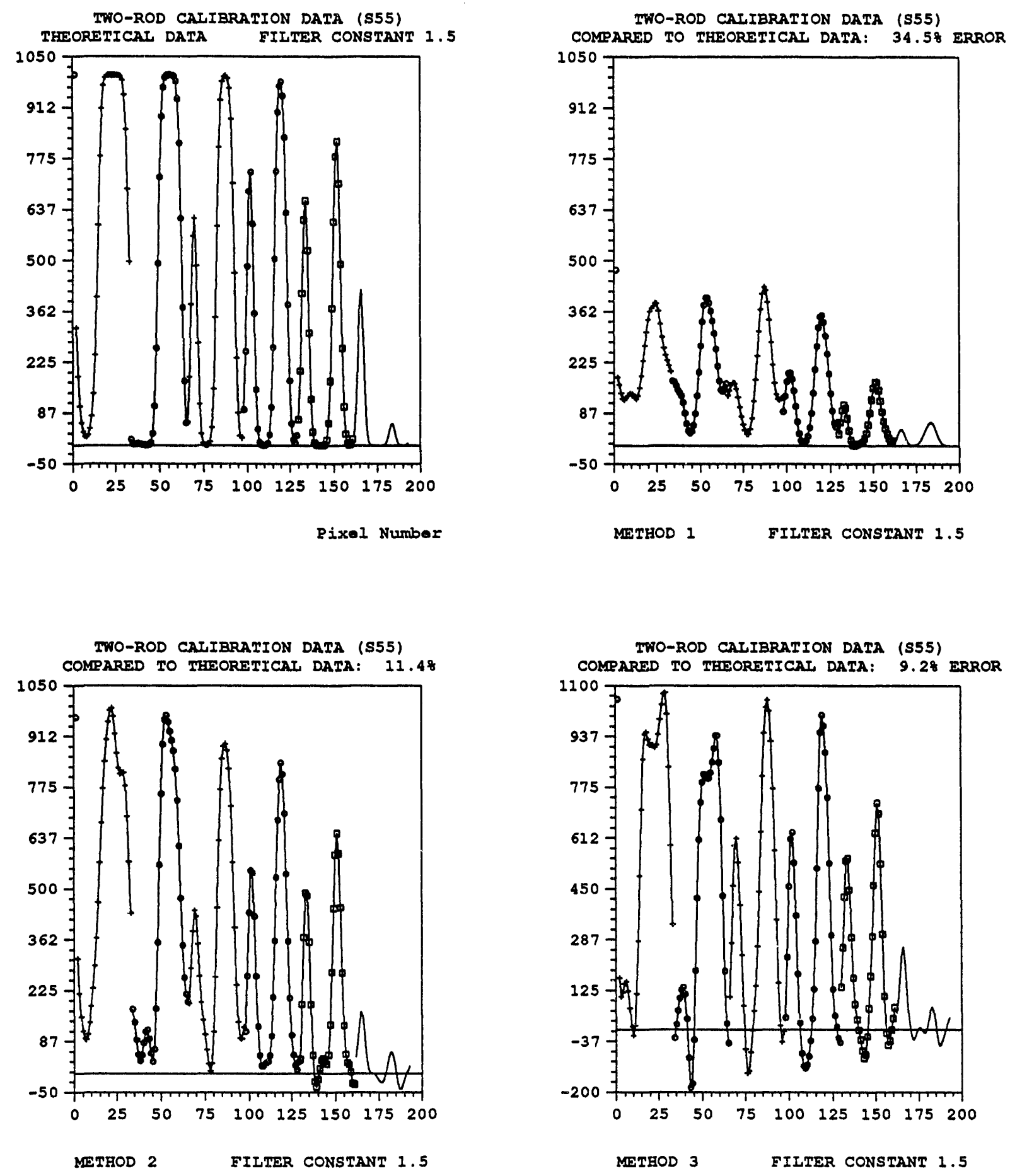

\section{FIGURE 6. COMPARISON OF METHODS \\ FOR A TWO ROD CALIBRATION}



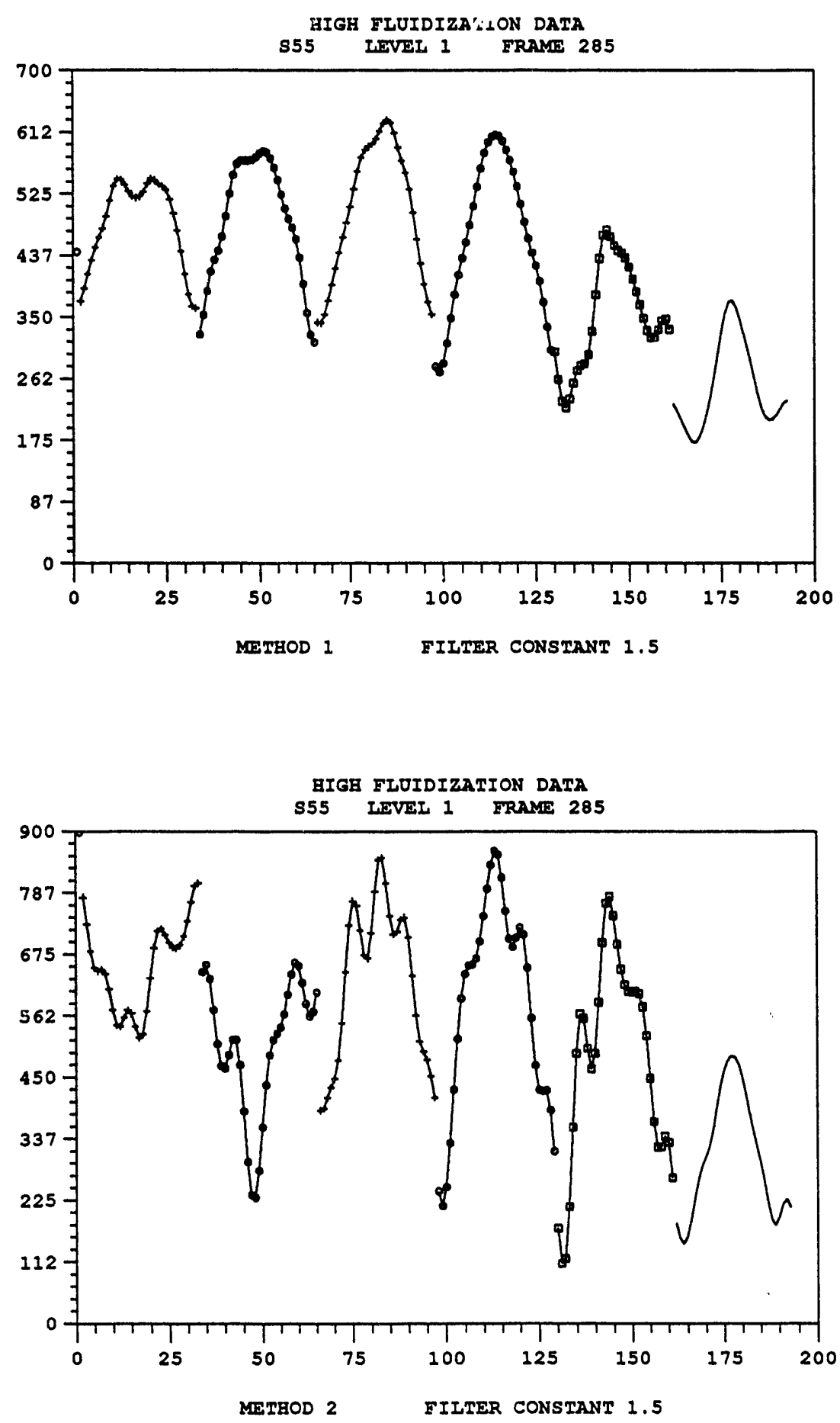

FIGURE 7. COMPARISON OF METHODS FOR A SET OF FLUIDIZATION DATA (S55) 


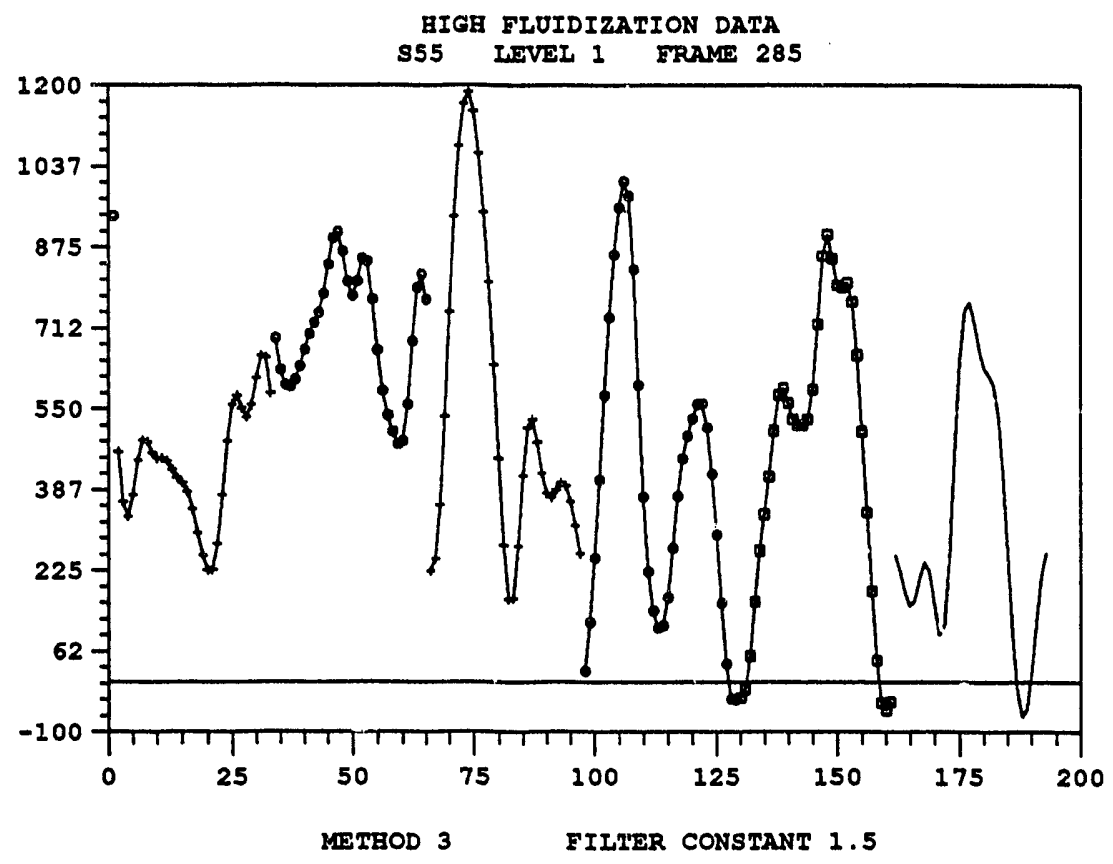

FIGURE 8. COMPARISON OF METHODS

FOR A SET OF FLUIDIZATION DATA (S55) 

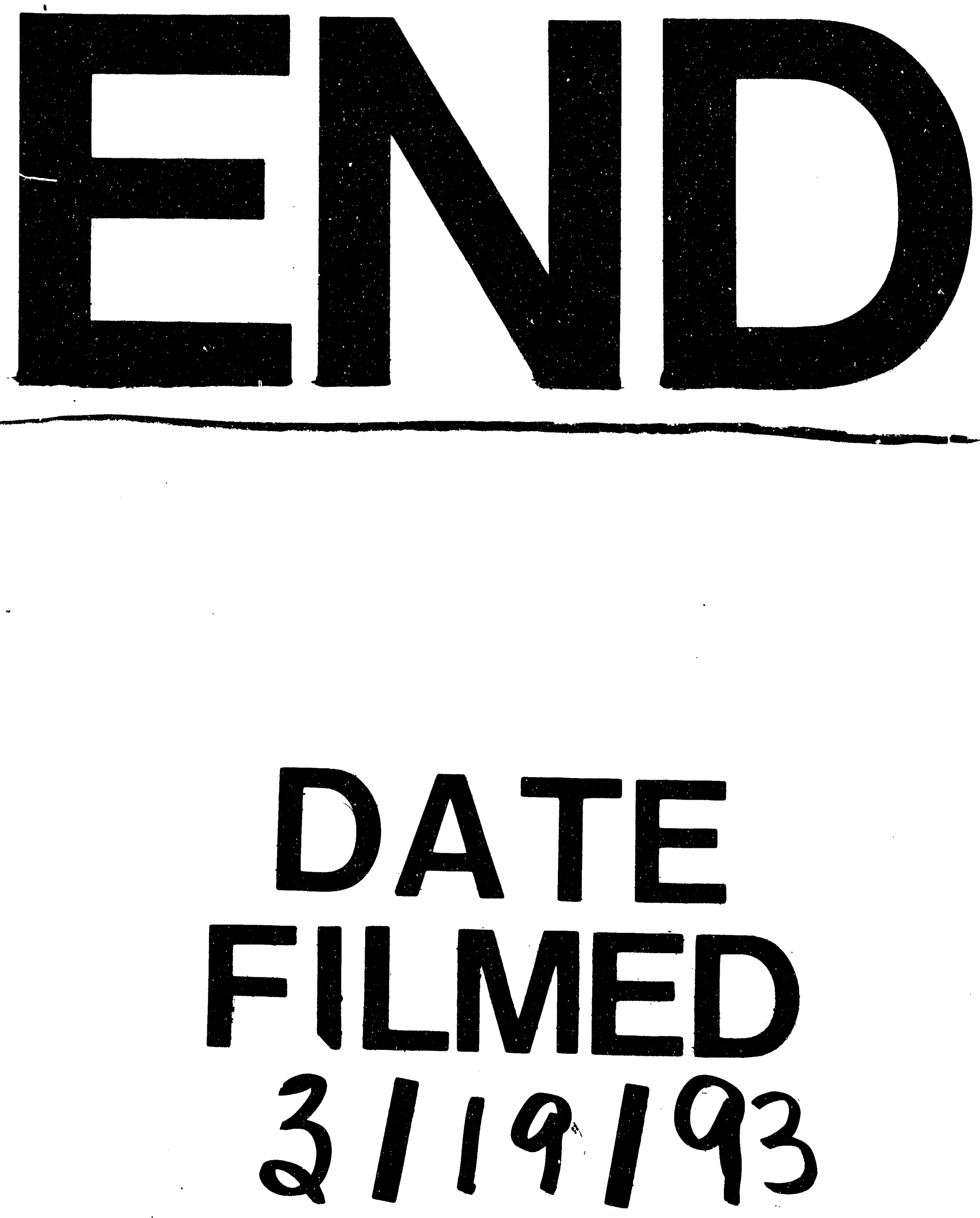